\title{
Tissue Inhibitor of Metalloproteinase-3 Regulates Inflammation in Human and Mouse Intestine
}

\author{
IVAN MONTELEONE, ${ }^{*}$ MASSIMO FEDERICI, ${ }^{*}$ MASSIMILIANO SARRA, ${ }^{*}$ ELEONORA FRANZĖ, ${ }^{*}$ VIVIANA CASAGRANDE, \\ FRANCESCA ZORZI, ${ }^{*}$ MICHELE CAVALERA, ${ }^{*}$ ANGELAMARIA RIZZO, ${ }^{*}$ RENATO LAURO, ${ }^{*}$ FRANCESCO PALLONE, \\ THOMAS T. MacDONALD, ${ }^{\ddagger}$ and GIOVANNI MONTELEONE*
}

${ }^{*}$ Dipartimento di Medicina dei Sistemi, Università Tor Vergata, Rome, Italy; ${ }^{\ddagger}$ Centre for Immunology and Infectious Disease, Blizard Institute of Cell and Molecular Science, Barts and the London School of Medicine and Dentistry, London, United Kingdom

BACKGROUND \& AIMS: Tissue inhibitor of metalloproteinases (TIMP)-3 is an inhibitor of matrix metalloproteinases, which regulates tissue inflammation, damage, and repair. We investigated the role of TIMP-3 in intestinal inflammation in human beings and mice. METHODS: We used real-time polymerase chain reaction and flow cytometry to measure levels of TIMP-3 in intestine samples from patients with Crohn's disease (CD) and those without (controls). We also analyzed TIMP-3 levels in lamina propria mononuclear cells (LPMCs) collected from biopsy samples of individuals with or without CD (controls) and then stimulated with transforming growth factor (TGF)- $\beta 1$, as well as in biopsy samples collected from patients with $\mathrm{CD}$ and then incubated with a Smad7 anti-sense oligonucleotide (knock down). LPMCs and biopsy samples from patients with CD were cultured with exogenous TIMP-3 and levels of inflammatory cytokines were measured. We evaluated the susceptibility of wild-type, TIMP-3knockout (TIMP-3-KO), and transgenic (TIMP-3-Tg) mice to induction of colitis with 2, 4, 6-trinitrobenzenesulfonic-acid (TNBS), and the course of colitis in recombinase-activating gene-1-null mice after transfer of wildtype or TIMP-3-KO T cells. RESULTS: Levels of TIMP-3 were reduced in intestine samples from patients with $\mathrm{CD}$ compared with controls. Incubation of control LPMCs with TGF- $\beta 1$ up-regulated TIMP-3; knockdown of Smad7, an inhibitor of TGF- $\beta 1$, in biopsy samples from patients with CD increased levels of TIMP-3. Exogenous TIMP-3 reduced levels of inflammatory cytokines in CD LPMCs and biopsy samples. TIMP-3-KO mice developed severe colitis after administration of TNBS, whereas TIMP-3-Tg mice were resistant to TNBS-induced colitis. Reconstitution of recombinase-activating gene-1-null mice with $\mathrm{T}$ cells from TIMP-3-KO mice increased the severity of colitis, compared with reconstitution with wild-type T cells. CONCLUSIONS: TIMP-3 is down-regulated in inflamed intestine of patients with CD. Its expression is regulated by TGF- $\beta 1$, and knock-down of Smad7 in intestinal tissues from patient with CD up-regulates TIMP-3. Loss or reduction of TIMP-3 in mice promotes development of colitis.

Keywords: ADAM; Mouse Model; IBD; Ulcerative Colitis.
C rohn's disease (CD) and ulcerative colitis (UC), the main forms of inflammatory bowel disease (IBD) in human beings, are chronic relapsing disorders with no known cure. ${ }^{1}$ It is thought that IBD results from excessive immune reactivity within the intestinal wall, perhaps directed against the endogenous intestinal microbiota. ${ }^{1}$ Downstream damage such as epithelial injury and ulceration are thought to be caused by cytokine-mediated alterations in the balance between matrix metalloproteinases (MMPs) and tissue inhibitors of MMPs (TIMPs), resulting in degradation of the lining of the gut. ${ }^{2-4}$ Particularly overexpressed in IBD mucosa are MMP-1, MMP-2, MMP-3, MMP-7, MMP-8, MMP-9, MMP-10, and MMP-12, which together have the ability to cleave virtually all components of the extracellular matrix., ${ }^{2,5,6}$ Of the 4 members of the TIMP family, TIMP-3 is unique in that it is extracellular matrix-bound and inhibits not only MMPs, but also several members of the a disintegrin and metalloproteinase domain (ADAM) family,7,8 some of which (eg, ADAM-10, ADAM-17, and ADAM-19) have $\alpha$-secretase activity.7,8 ADAM-17, also known as tumor necrosis factor (TNF)- $\alpha$-converting enzyme (TACE), cleaves the transmembrane TNF- $\alpha$ precursor, producing soluble TNF- $\alpha,{ }^{7}$ and other transmembrane molecules such as epidermal growth factor-receptor ligands, TGF- $\alpha$, L-selectin, and interleukin (IL)-6 signaling pathway-related molecules. ${ }^{8,9}$ In $\mathrm{T}$ cells, TACE cleaves the negative regulatory protein lymphocyte-activation gene 3 (LAG-3), enhancing T-cell proliferation and cytokine production. ${ }^{10}$ Because MMPs and ADAMs regulated by TIMP-3 are involved in several biological processes ${ }^{11-15}$ it is tempting to speculate that TIMP-3 may play a critical role in the control of inflammation, tissue damage, and repair. Indeed, TIMP3-knockout (KO) mice have increased TACE activity and increased soluble TNF- $\alpha$ levels, and an enhanced potential

\footnotetext{
Abbreviations used in this paper: ADAM, a disintegrin and metalloproteinase domain; CD, Crohn's disease; EGFR, epidermal growth factor receptor; IBD, inflammatory bowel disease; IFN, interferon; IL, interleukin; KO, knock out; LPMC, lamina propria mononuclear cell; MMP, matrix metalloproteinases; rh, recombinant human; TACE, tumor necrosis factor- $\alpha$-converting enzyme; Tg, transgenic; TIMP, tissue inhibitor of metalloproteinase; TNBS, 2, 4, 6-trinitrobenzene-sulfonic-acid; TNF, tumor necrosis factor; UC, ulcerative colitis; WT, wild-type.

$$
\text { (C) } 2012 \text { by the AGA Institute }
$$$$
0016-5085 / \$ 36.00
$$

http://dx.doi.org/10.1053/j.gastro.2012.07.016 
for inflammation in adipose tissue, liver, lung, and joints. ${ }^{16-19}$ TACE activity is increased in the mucosa of patients with $\mathrm{IBD},{ }^{20,21}$ and in rats with 2, 4, 6-trinitrobenzene sulfonic acid (TNBS) colitis. ${ }^{22}$ There have been descriptive studies of TIMP-3 in gut inflammation, ${ }^{6}$ we examined how TIMP-3 is expressed and regulated in the gut of patients with IBD and whether TIMP-3 is a critical regulator of gut inflammation both in human beings and the mouse.

\section{Materials and Methods}

\section{Mucosal Samples}

Mucosal biopsy specimens were taken from involved areas of 30 patients with active $\mathrm{CD}$ (median age, $35 \mathrm{y}$, range, $25-55 y$ ). In 6 of the $30 \mathrm{CD}$ patients, paired biopsy samples were taken from endoscopically inflamed and uninflamed mucosa. Eleven $C D$ patients were receiving corticosteroids, and the remaining patients were on mesalazine. Resected intestinal tissue was taken from 8 patients with severe disease poorly responsive to medical treatment and used to isolate lamina propria mononuclear cells (LPMCs). Biopsy specimens also were taken from 18 patients with active UC (median age, $36 \mathrm{y}$; range, 26-55 y). Six of these patients were receiving corticosteroids and the remaining patients were receiving mesalazine. All biopsy specimens routinely were processed by $\mathrm{H} \& \mathrm{E}$ staining and interpreted by a single blinded gastrointestinal pathologist in random order. The histologic activity of UC biopsy specimens was quantified using the scoring system published by Geboes et al. ${ }^{23}$ The mean grades for such samples ranged from 2 to 4 . For CD biopsy specimens, an overall inflammation score was assigned as described previously. ${ }^{24}$ The score ranged from 0 to 16 , where 0 represented normal and 16 represented severely inflamed. The score includes features of acute and chronic inflammatory changes, epithelial damage, infiltration of polymorphonuclear and mononuclear cells in the lamina propria, and the presence of granuloma. The histologic score for biopsy specimens taken from macroscopically inflamed areas ranged from 10 to 13 . Normal controls included biopsy specimens of 18 patients with irritable bowel syndrome and macroscopically and microscopically unaffected colonic specimens of 8 patients undergoing resection for colon cancer (median age, 41 y; range, 29-69 y). Approval was obtained from the local ethics committee.

\section{LPMC Isolation and Culture}

All reagents were from Sigma-Aldrich (Milan, Italy) unless specified otherwise. LPMCs were isolated as described previously $^{25}$ and cultured in RPMI 1640 supplemented with $10 \%$ fetal bovine serum, penicillin $(100 \mathrm{U} / \mathrm{mL})$, and streptomycin $(100 \mathrm{U} / \mathrm{mL})$. For studies with TGF- $\beta 1$ or Smad7, antisense oligonucleotide cells were incubated in ex vivo serum-free medium (Lonza, Verviers, Belgium) supplemented with penicillin/ streptomycin. Normal LPMCs were incubated with TGF- $\beta 1$ (final concentration, $1-4 \mathrm{ng} / \mathrm{mL} ; \mathrm{R} \& \mathrm{D}$ Systems, Minneapolis, MN) for 24-36 hours. CD LPMCs were pre-incubated with recombinant human(rh)-Timp-3 (final concentration, 25-100 ng/mL; $\mathrm{R} \& \mathrm{D}$ Systems) for 1 hour and then stimulated with activating CD3/CD28 antibody-coated beads (Miltenyi Biotec, Bergisch Gladbach, Germany) for 24 hours. In addition, CD LPMCs were cultured with or without Smad7 sense or antisense oligonucleotide $(10 \mu \mathrm{g} / \mathrm{mL})$ using Lipofectamine 2000 (Invitrogen, Carlsbad, CA) for 36 hours. Details of the Smad7 antisense and sense oligonucleotides have been described elsewhere. ${ }^{26}$

\section{RNA Extraction, Complementary DNA Preparation, and Real-Time Polymerase Chain Reaction}

Studies were performed as indicated in the Supplementary Materials and Methods section.

\section{Immunohistochemistry}

Studies were performed as indicated in the Supplementary information.

\section{Ex Vivo Organ Culture}

Mucosal samples taken from 4 normal controls and 2 $\mathrm{CD}$ patients were cultured in the presence or absence of TGF- $\beta 1$ $(5 \mathrm{ng} / \mathrm{mL})$ for 24 hours. Biopsy specimens taken from CD patients were cultured with Smad7 sense or antisense oligonucleotides $(10 \mu \mathrm{g} / \mathrm{mL})$ for 40 hours or with rh-TIMP-3 (50 ng/ $\mathrm{mL}$ ) for 24 hours. Organ culture was performed as described elsewhere. ${ }^{26}$

\section{Protein Extraction and $\alpha$-Secretase Activity}

$\alpha$-secretase activity was determined in biopsy specimens from $19 \mathrm{CD}$ patients, 16 UC patients, and 18 normal controls using a commercially available Kit (AnaSpec, San Jose, CA) as described elsewhere. ${ }^{17}$ Total proteins $(30 \mu \mathrm{g})$ were used for the assay and the reaction was started by adding $40 \mu \mathrm{mol} / \mathrm{L}$ of the fluorophoric QXL520/5FAM FRET substrate (ANASPEC, San Josè, CA). Fluorescence of the $\alpha$-secretase cleavage product was measured in a fluorescence microplate reader (FLx800; BIO-TEK Instruments, Winooski, VT) at excitation spectra/( $\lambda$ ex) (lex) 490 $\mathrm{nm}$ and emission spectra/( $\lambda$ ex) (lem) $520 \mathrm{~nm}$.

\section{TNBS-Induced Colitis}

Wild-type, TIMP-3-transgenic (Tg), and TIMP-3-KO mice (see Supplementary information) on a C57BL/ 6 background were injected intrarectally with either 2 or $3 \mathrm{mg}$ TNBS in $50 \%$ ethanol. Controls consisted of mice treated with $50 \%$ ethanol. Weight changes were recorded daily, mice were killed at day 4 , and tissues were collected for histology, RNA analysis, and LPMC isolation. The colitis histologic score was calculated as described elsewhere. ${ }^{27}$ To determine whether TNF- $\alpha$ mediates the colitic effect in TIMP-3-KO mice, a neutralizing murine anti-TNF- $\alpha(450 \mu \mathrm{g} /$ mouse; R\&D Systems) or nonrelevant control antibody (450 $\mu \mathrm{g} /$ mouse; R\&D Systems) was administered intraperitoneally 6 hours before TNBS treatment.

\section{Transfer Colitis in Recombinase-Activating Gene-1 Null Mice}

$\mathrm{CD} 4+\mathrm{CD} 25-\mathrm{CD} 62 \mathrm{~L}+\mathrm{T}$ cells, isolated from the spleen of TIMP-3-KO and TIMP-3-wild-type (WT) mice using the mouse naive T-Cell Isolation Kit (Miltenyi Biotech, purity $>$ $98 \%$ ), were resuspended in phosphate-buffered saline and injected intraperitoneally $\left(4 \times 10^{5}\right.$ cells/mouse $)$ into Bl/ 6 recombinase-activating gene-1-deficient mice. Mice were observed daily and weighed weekly and killed after 4 weeks. Colitis was scored as described elsewhere. ${ }^{28}$

\section{Flow Cytometry}

Studies were performed as indicated in the Supplementary information. 


\section{Enzyme-Linked Immunosorbent Assay for TNF- $\alpha$}

Studies were performed as indicated in the Supplementary information.

\section{Statistical Analysis}

Differences between groups were compared using the Student $t$ test or the Spearman test.

\section{Results}

\section{Down-regulation of TIMP-3 Expression in CD}

TIMP-3 transcripts were reduced in CD as compared with UC and normal samples (Figure 1A). TIMP-3 RNA expression did not differ between UC and controls (Figure 1A). In CD, decreased TIMP-3 RNA expression was restricted to areas of active inflammation (Figure 1A), and the same biopsy specimens showed enhanced $\alpha$-secretase activity (Figure $1 B$ ). Moreover, we analyzed TACE and ADAM-15 in the same intestinal samples used to evaluate TIMP-3. Data from these experiments show that TACE and ADAM-15 transcripts were up-regulated in IBD (Supplementary Figure 1). The IBD and control samples used for TIMP-3 analysis then were tested for the expression of TNF- $\alpha$. TNF- $\alpha$ transcripts were significantly higher in both $\mathrm{CD}$ and UC than in controls (Supplementary Figure 2A), thus confirming that IBD biopsy specimens were taken from inflamed areas. By immunohistochemistry we next showed that TIMP-3 was expressed both in epithelial cells and in lamina propria cells in normal controls, and that in CD inflamed mucosa there was a uniform and considerable reduction of TIMP-3 expression in all cells (Supplementary Figure 3). No correlation between TIMP-3 expression and presence of granulomas was seen in CD (not shown). Moreover, immunohistochemistry revealed no significant difference in TACE-expressing cells between IBD and controls (Supplementary Figure 3). Flow-cytometric analysis of LPMCs confirmed that TIMP-3 was diminished in CD, particularly in CD3+ and CD68+ cells (Figure 1C), but not in neutrophils Ly-6G+ or CD19+ B cells (Supplementary Figure 4).

Because TGF- $\beta 1$ enhances TIMP- 3 in fibroblasts, ${ }^{29}$ we determined if TGF- $\beta 1$ regulates TIMP- 3 expression in the human gut. TGF- $\beta 1$ dose-dependently enhanced TIMP-3 RNA and protein in normal LPMCs (Figure 1D), and increased TIMP-3 transcripts in normal but not in CD explants (Supplementary Figure 5). In CD mucosa, TGF- $\beta 1$ activity is reduced because of high levels of Smad7, a specific inhibitor of TGF- $\beta 1$ signaling. ${ }^{26}$ Thus, we determined if low TIMP-3 expression was owing to defective TGF- $\beta 1$ signaling. Smad7 antisense oligonucleotide reduced Smad7 in CD LPMCs and enhanced TIMP-3 expression in LPMCs and explants (Figure $1 E-F$ ). These data suggest that decreased TIMP-3 expression in $\mathrm{CD}$ is maintained by diminished TGF- $\beta 1$ activity owing to high Smad7.

\section{Recombinant TIMP-3 Delivers Anti- inflammatory Signals in CD Mucosa}

We next examined whether rh-TIMP-3 reduced proinflammatory cytokine synthesis in CD. Treatment of CD LPMCs with rh-TIMP-3 increased the frequency of membrane TNF- $\alpha$ expressing LPMCs because TIMP-3 inhibits TACE, thereby blocking membrane TNF (mTNF) cleavage (Figure 2A). rh-TIMP-3 significantly and dose-dependently reduced anti-CD3/CD28-stimulated IL-6, interferon (IFN)- $\gamma$, and IL-17A expression (Figure $2 B-D$ ). In the same cell cultures, rh-TIMP-3 did not affect the fraction of apoptotic/necrotic cells (Figure $2 E$ ). No significant change in the frequency of IL-10 - and FoxP-3-positive cells was seen after rh-TIMP-3 treatment (not shown). Rh-TIMP-3 significantly inhibited transcripts for IL-6, IFN- $\gamma$, IL-17A, and TNF- $\alpha$ in CD explants (Figure 2F). Together these findings suggest that the reduced TIMP-3 levels in CD may contribute to the inflammatory response.

\section{TIMP-3-KO Mice Develop Severe TNBS Colitis}

We next investigated if TIMP-3 deficiency aggravates experimental colitis in mice, using the TNBS model. TIMP-3 expression was decreased in the colon of wild-type mice with TNBS colitis compared with noncolitic mice (Figure 3A). After TNBS administration, TIMP-3-KO mice showed greater loss of body weight compared with wild-type mice (Figure $3 B$ ). There was no significant difference in body weight between wild-type and TIMP-3-KO mice after ETOH treatment (Figure $3 B$ ). A significant increase in $\alpha$-secretase activity was seen in colonic extracts of TIMP3-KO mice (Figure 3C). Histologic examination of colonic tissues and histologic scoring of colitis showed greater inflammation in TIMP-3-KO mice as compared with wild-type mice (Figure 3D). Consistently, IFN- $\gamma$ and IL-17A were increased significantly in the colon of wild-type mice with TNBS colitis in comparison with noncolitic mice (Figure $3 E-F)$. The percentage of IL-6 - expressing cells also significantly was increased in TNBS-treated mice, although IL-6 transcripts were only slightly enhanced (Figure $3 E-F$ ). Transcripts for IFN- $\gamma$, IL-17A, and IL-6, and the fraction of cytokine-secreting cells were increased significantly in colitic TIMP-3-KO mice as compared with wild-type mice with colitis (Figure $3 E-F$ ).

We hypothesized that the severe colitis seen in TIMP$3-\mathrm{KO}$ mice in part could be owing to amplification of ADAM-mediated processing of membrane-bound TNF- $\alpha$ into its soluble form. ${ }^{7}$ TIMP-3-KO mice expressed higher levels of TNF- $\alpha$ compared with wild-type mice (Figure $4 A$ ). TIMP-3-KO mice given a neutralizing TNF- $\alpha$ antibody had reduced loss of body weight, milder histologic disease, and diminished expression of IL-6, IFN- $\gamma$, and TNF- $\alpha$ compared with IgG-treated mice (Figure $4 B-F$ ). In contrast, mice treated with anti-TNF- $\alpha$ showed no significant decrease in IL-17A expression (Figure 4D and E). 
A

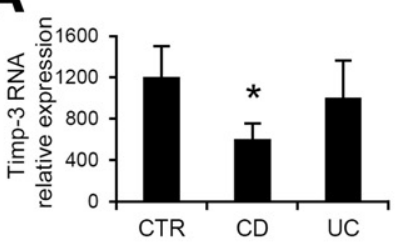

C

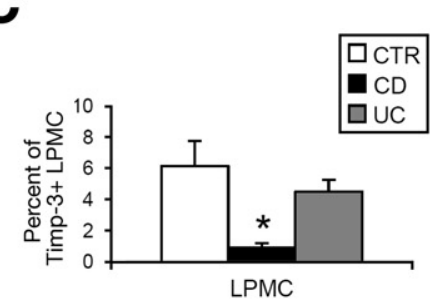

D

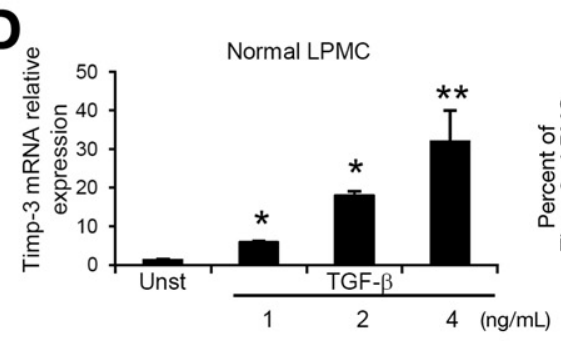

B

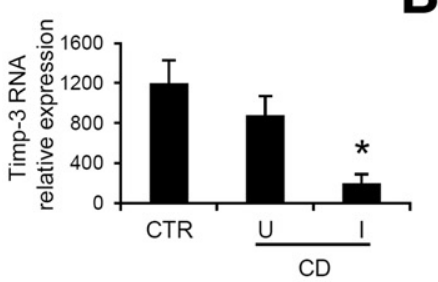

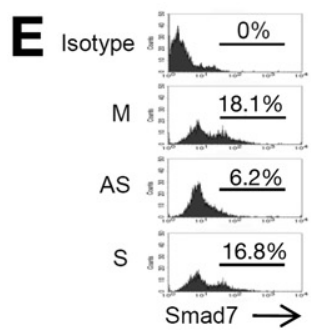

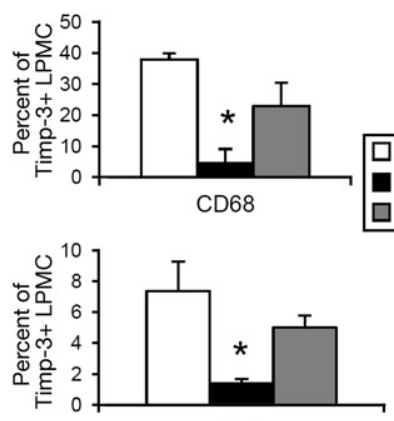

CD3+
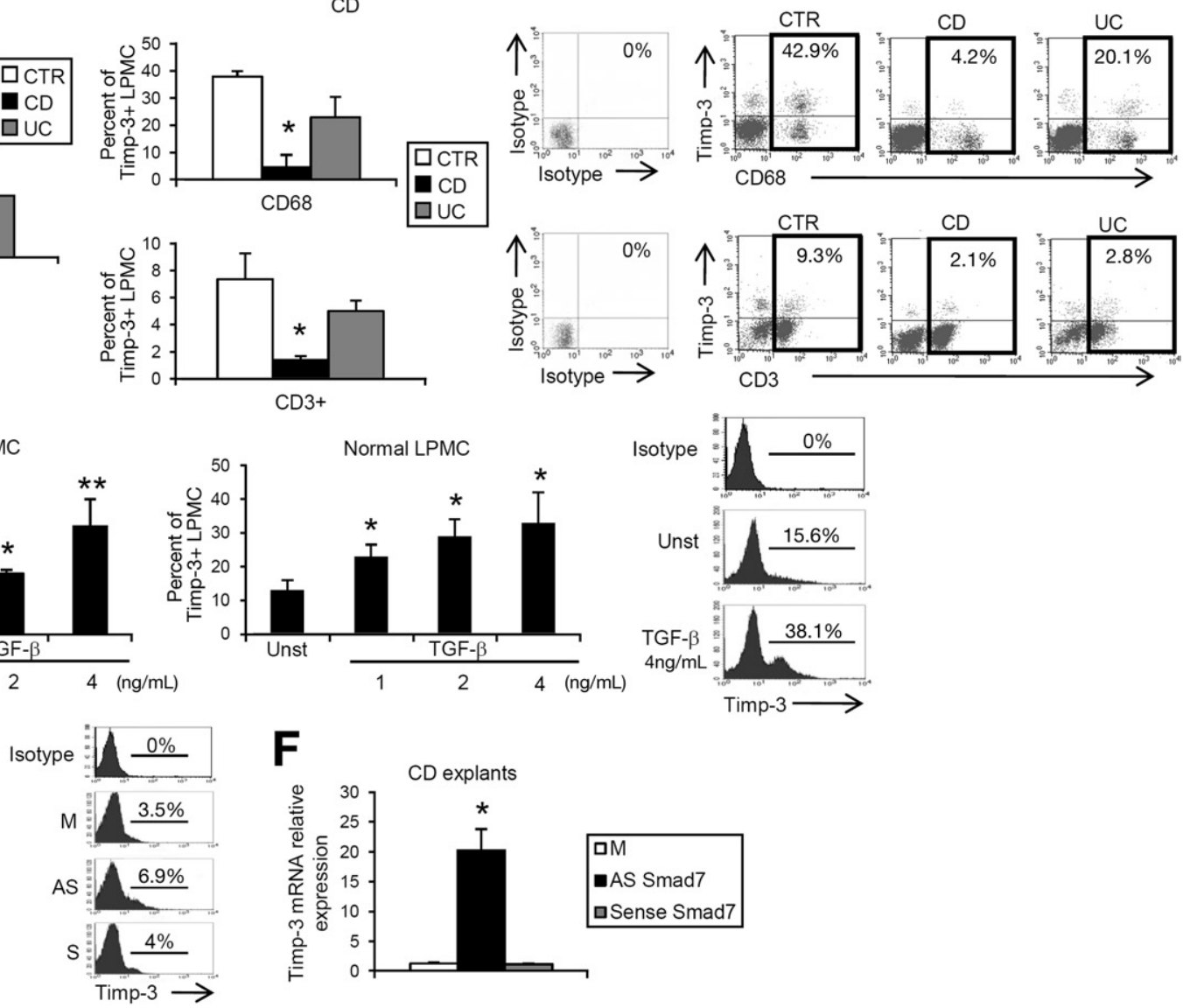

Figure 1. (A) TIMP-3 expression is reduced in CD intestinal mucosa. Left: transcripts for TIMP-3 were evaluated in biopsy specimens taken from 12 normal controls (CTR), 12 patients with $C D(C D)$, and 12 patients with $U C(U C)$ by real-time polymerase chain reaction and normalized to $\beta$-actin. Data indicate mean \pm standard deviation of all experiments. CD vs CTR or UC $\left({ }^{*} P<.04\right)$. In the right graph, transcripts for TIMP-3 were evaluated in samples taken from 6 normal controls and from uninflamed $(U)$ and inflamed $(I)$ areas of 6 CD patients by real-time polymerase chain reaction. Data indicate mean \pm standard deviation of all experiments. Inflamed vs uninflamed $(P=.02)$. (B) The activity of $\alpha$-secretases, measured by a fluorimetric assay in 18 normal controls, $19 \mathrm{CD}$ patients, and $16 \mathrm{UC}$ patients, is enhanced in inflamed CD intestinal mucosa. Data indicate mean \pm standard deviation of all experiments. ${ }^{*} \mathrm{CD}$ vs CTR or UC $(P<.005)$. (C) Flow cytometry analysis of TIMP-3 in colonic LPMCs, CD3+, and CD68+ cells isolated from 4 normal controls (CTR), 4 CD patients, and 4 UC patients. Data indicate mean \pm standard deviation of all experiments. Asterisk respresents CD vs UC $(P=.03)$; CD vs CTR $(P=.02)$. Right inset shows representative histograms of TIMP-3-expressing CD3+ and CD68+ cells isolated from $1 \mathrm{CTR}, 1 \mathrm{CD}$ patient, and $1 \mathrm{UC}$ patient. Staining with an isotype control lgG also is shown. Numbers in the selected areas indicate the percentages of positive cells. (D) TGF- $\beta 1$ increases TIMP-3 in normal LPMCs. Left: Cells were incubated with increasing doses of TGF- $\beta 1$ for 24 hours and then examined for TIMP-3 RNA by real-time polymerase chain reaction and normalized to $\beta$-actin. Data indicate mean \pm standard deviation of all experiments. TGF- $\beta 1$ vs unstimulated ( ${ }^{*} P<.04 ;{ }^{* *} P=.01$ ). Right: flow cytometry analysis of TIMP-3-expressing LPMCs stimulated with TGF- $\beta 1$ for 36 hours. Data indicate mean \pm standard deviation of all experiments. TGF- $\beta 1$ vs unstimulated $(* P<.04)$. Inset shows representative histograms of TIMP-3-expressing LPMCs isolated from 1 normal control and cultured with or without (unst) TGF- $\beta 1$. Numbers above lines indicate the percentages of positive cells. Staining with a control lgG also is shown. (E) Knock-down of Smad7 enhances TIMP-3 in CD LPMCs. Cells were incubated with medium (M), Smad7 sense (S), or antisense (AS) oligonucleotides and then examined for Smad7 (left) and TIMP-3 (right) by flow cytometry. Numbers above lines indicate the percentages of positive cells. One of 3 separate experiments in which similar results were obtained is shown. ( $F$ ) TIMP-3 is enhanced in CD biopsy specimens by Smad7 AS. Intestinal biopsy specimens taken from 3 CD patients were incubated with medium (M), Smad7 antisense (AS), or sense (S) oligonucleotides for 40 hours and then analyzed for TIMP-3 by real-time polymerase chain reaction. Data indicate mean \pm standard deviation of all experiments. AS vs S or Unst $(P<.006)$. 

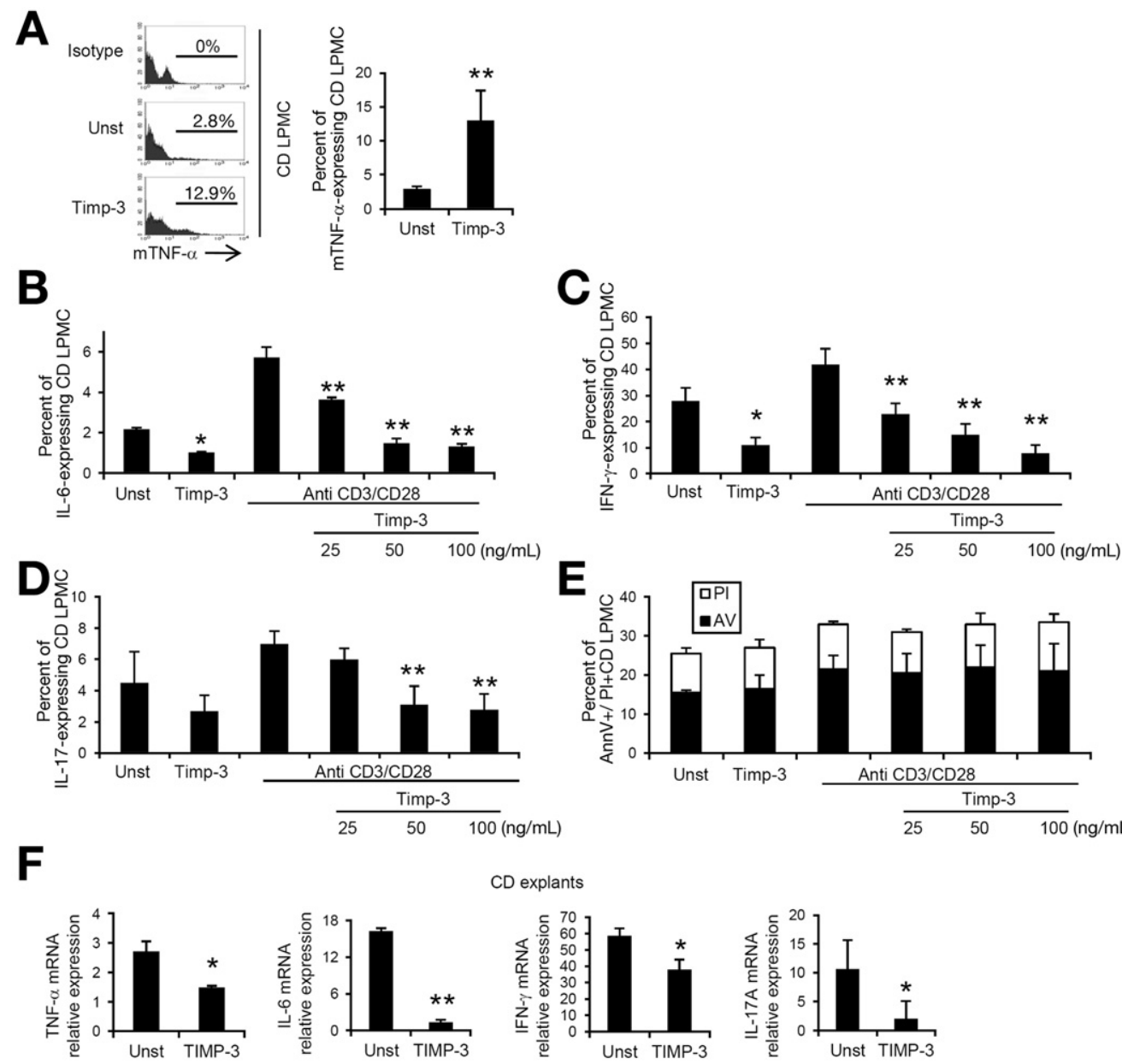

Figure 2. (A) Exogenous TIMP-3 enhances membrane-bound (m)TNF- $\alpha$ on CD LPMCs. Left: representative histograms of mTNF- $\alpha-$ positive LPMCs cultured with rh-Timp-3 for 36 hours and analyzed by flow cytometry. Numbers above lines indicate the percentages of positive cells. One of 3 separate experiments in which similar results were obtained is shown. Right: data indicate mean \pm standard deviation of 3 separate experiments. TIMP-3 vs unstimulated ( $\left.{ }^{\star \star} P=.01\right)$. (B-E) CD LPMCs treated with TIMP-3 express less inflammatory cytokines. Cells were either left unstimulated (Unst) or pre-incubated with TIMP-3 for 1 hour and then stimulated with activating CD3/CD28 antibody-coated beads. After 24 hours, cells were analyzed for $(B-D)$ cytokines and $(E)$ Annexin $V$ and propidium iodide (AV/PI). Data indicate mean \pm standard deviation of 4 separate experiments. TIMP-3 vs unstimulated ( $\left.{ }^{*} P<.04\right)$; anti-CD3/CD28 vs anti-CD3/CD28+ TIMP-3 ( $\left.{ }^{\star \star} P<.03\right)$. (F) Treatment of CD biopsy specimens with rh-TIMP-3 reduces inflammatory cytokine expression. Cytokine RNA was evaluated by real-time polymerase chain reaction and normalized to $\beta$-actin. Data indicate mean \pm standard deviation of 4 separate experiments $\left({ }^{\star} P=.04 ;{ }^{\star \star} P=.01\right)$.

\section{Overexpression of TIMP-3 in Myeloid Cells Attenuates TNBS Colitis, and TIMP-3-Deficient T Cells Induce Severe Colitis After Transfer Into Immunodeficient Mice}

Because TIMP-3 is expressed by intestinal macrophages, we determined the contribution of myeloid-associated TIMP-3 by using Tg mice expressing TIMP-3 under the CD68 promoter. TIMP-3 transcripts were increased in the colons of TIMP-3-Tg mice compared with wild-type mice after treatment with ETOH and ETOH+TNBS (Supplementary Figure 5A). TNBS-treated Tg mice expressed less TIMP-3 transcripts than ETOH-treated $\mathrm{Tg}$ mice (Supplementary Figure 6A), thus confirming the negative effect of colitis on TIMP-3 expression. TIMP3 -Tg mice showed less $\alpha$-secretase activity compared with wild-type mice after TNBS treatment (Supplementary Figure 6B). After TNBS treatment, TIMP-3-Tg mice devel- oped less weight loss, milder histologic disease, and reduced induction of inflammatory cytokines (Figure 5). These data suggest that overexpression of TIMP-3 is sufficient to attenuate TNBS colitis.

To evaluate the contribution of T-cell-derived TIMP-3 on the development of colitis, naive $\mathrm{T}$ cells isolated from wild-type and TIMP-3-KO mice were transferred into recombinase-activating gene-1-deficient mice. Mice reconstituted with naive $\mathrm{T}$ cells from both wild-type and TIMP$3-\mathrm{KO}$ mice showed weight loss starting after week 2; however, the weight loss in mice reconstituted with TIMP3 -deficient $\mathrm{T}$ cells was more marked than that seen in mice reconstituted with wild-type $\mathrm{T}$ cells (Figure 6A). A significant increase in $\alpha$-secretase activity was seen in colonic extracts of mice reconstituted with TIMP-3- deficient $\mathrm{T}$ cells (Figure $6 \mathrm{~A}$ ). In agreement with these clinical responses, mice receiving TIMP-3-deficient $\mathrm{T}$ cells had a more severe histologic inflammation (Figure $6 B$ ) and en- 

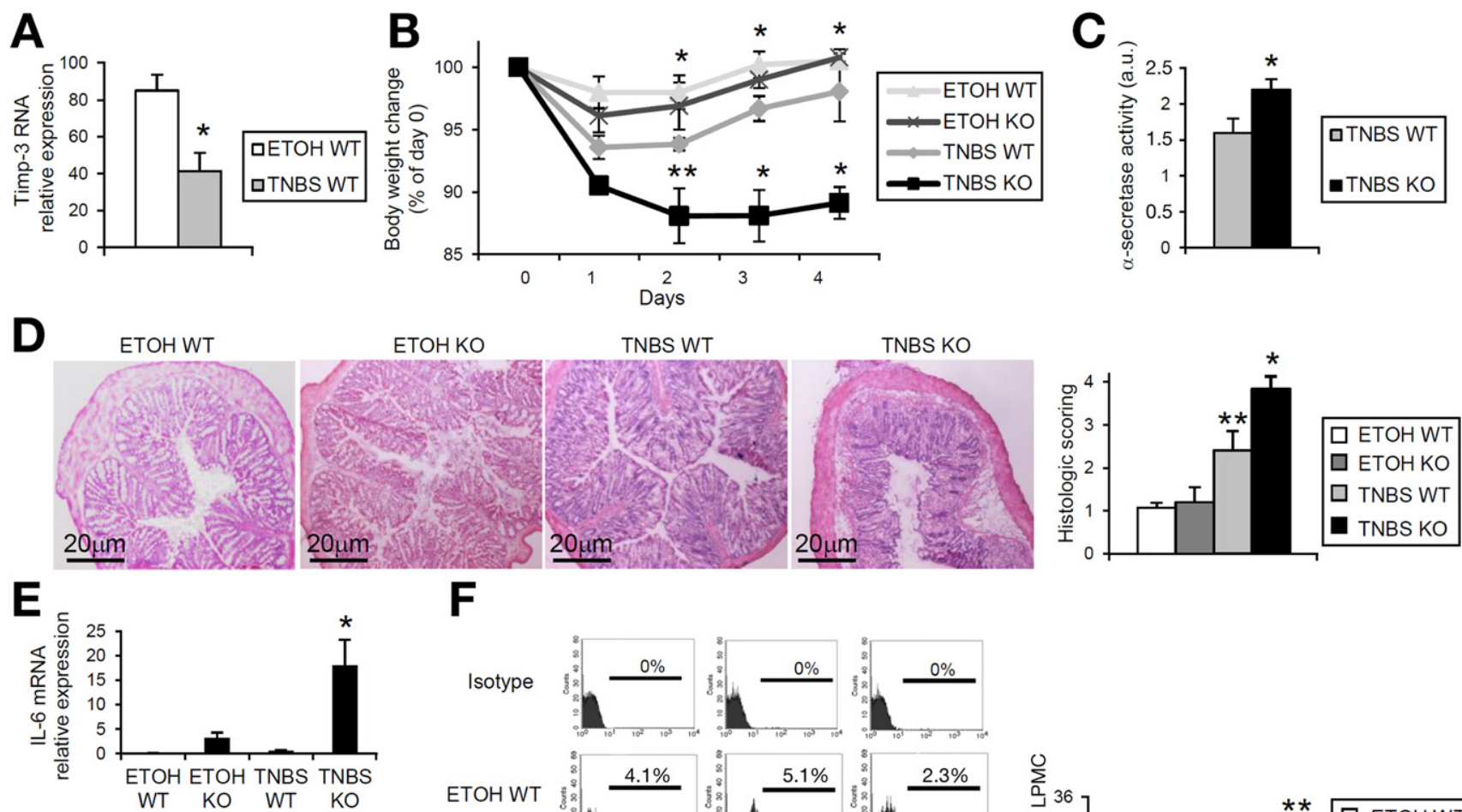

$\mathbf{F}$
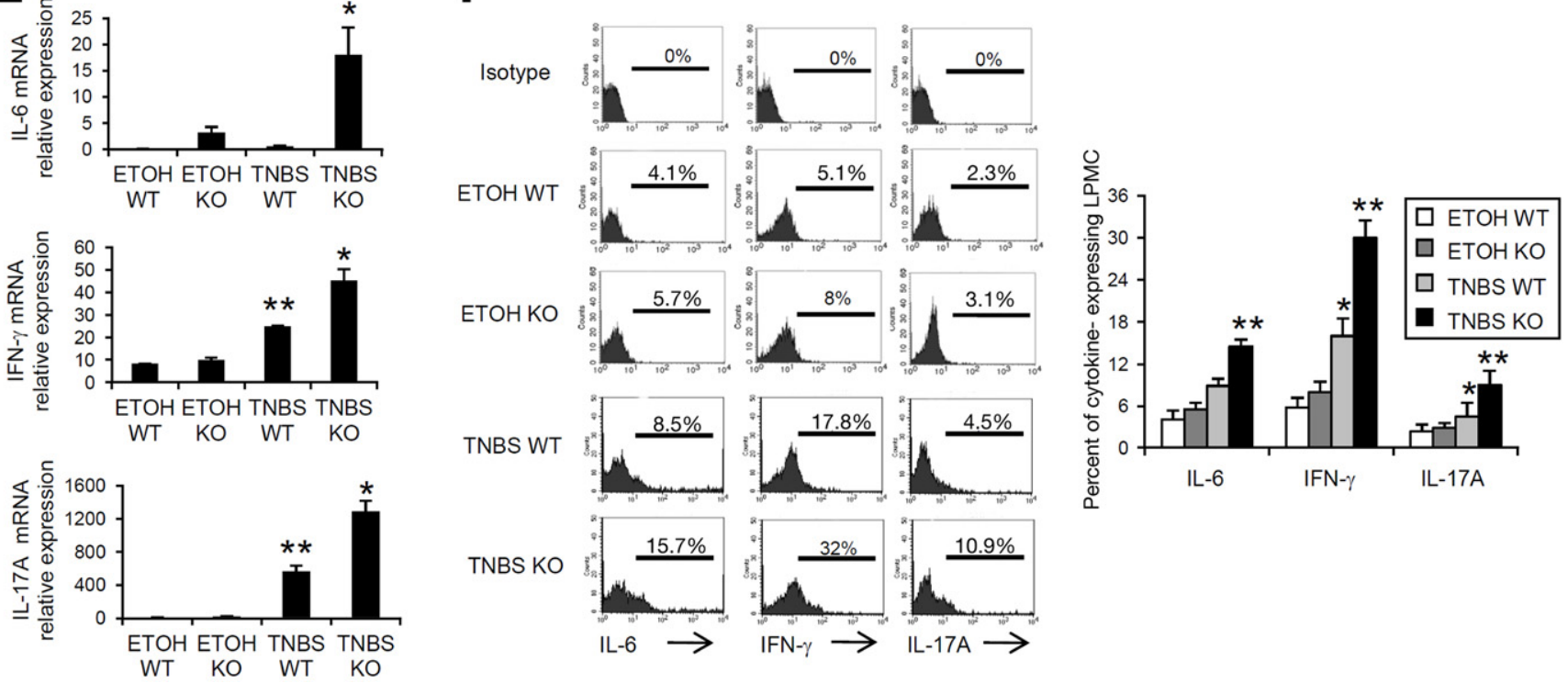

Figure 3. TIMP-3-KO mice are more susceptible to TNBS colitis. (A) TIMP-3 is reduced in wild-type mice with TNBS colitis. TIMP-3 RNA was evaluated in colonic samples taken from wild-type (WT) mice treated with ethanol (ETOH WT) or ETOH + TNBS (TNBS WT) by real-time polymerase chain reaction and normalized to $\beta$-actin $\left({ }^{*} P=.01\right)$. (B) TNBS colitis was induced in WT and TIMP-3-KO mice, and body weight was recorded daily. Each point on the graph indicates cumulative mean \pm standard deviation of 3 separate experiments. In each experiment at least 5 mice per group were used; TNBS WT vs ETOH WT ( $\left.{ }^{\star \star} P=.04\right)$, TNBS KO vs TNBS WT ${ }^{* \star} P=.02$ and $\left.{ }^{\star} P<.02\right)$. (C) $\alpha$-secretase activity in colonic tissues taken from WT and TIMP-3-KO mice and normalized to ETOH control mice. Data indicate mean \pm standard deviation of 4 separate experiments $\left({ }^{\star} P=.04\right)$. (D) Representative H\&E-stained colonic sections of control (ETOH-treated) and colitic (TNBS)- wild-type and TIMP-3-KO mice killed on day 4. Right inset shows the histologic score of the colonic sections taken from the 4 groups of mice. TNBS WT vs ETOH WT (** $P=.03)$, TNBS KO vs TNBS WT $\left({ }^{\star} P=.03\right)$. (E) TIMP-3-KO mice with TNBS colitis show increased expression of inflammatory cytokines. Cytokine transcripts were analyzed in colonic samples of controls $(\mathrm{ETOH})$ and colitic WT and TIMP-3-KO mice by real-time polymerase chain reaction. Data indicate mean \pm standard deviation of all experiments. TNBS WT vs ETOH WT ( $\left.{ }^{\star \star} P<.04\right)$, TNBS KO vs TNBS WT $\left({ }^{\star} P<.03\right)$. ( $F$ ) Representative histograms of IL-6, IFN- $\gamma$, and IL-17A-expressing LPMCs isolated from control (ETOH) and colitic (TNBS) WT and KO mice and analyzed by flow cytometry. Staining with an isotype control lgG also is shown. Right inset shows mean \pm standard deviation of all experiments $(\mathrm{N}=3)$ depicted in F: TNBS WT vs ETOH WT ( $P<$.04), TNBS KO vs TNBS WT (**P<.03).

hanced expression of inflammatory cytokines in the colon (Figure 6C and $D$ ).

\section{Discussion}

This study set out to determine if TIMP-3 is a determinant of human and mouse gut inflammation. We first showed that TIMP-3 expression was decreased in CD mucosa, particularly in T cells, CD68+ cells, and also in epithelial cells. CD samples consistently showed enhanced $\alpha$-secretase activity, suggesting that the improved $\alpha$-secretase activity present in $\mathrm{CD}$ gut mucosa is the result of a reduced expression of TIMP-3. There was no difference in TIMP-3 expression and $\alpha$-secretase activity between UC samples and controls, suggesting that down-regulation of TIMP-3 in CD is not a product of inflammation per se. These results conflict with a previous study in which 


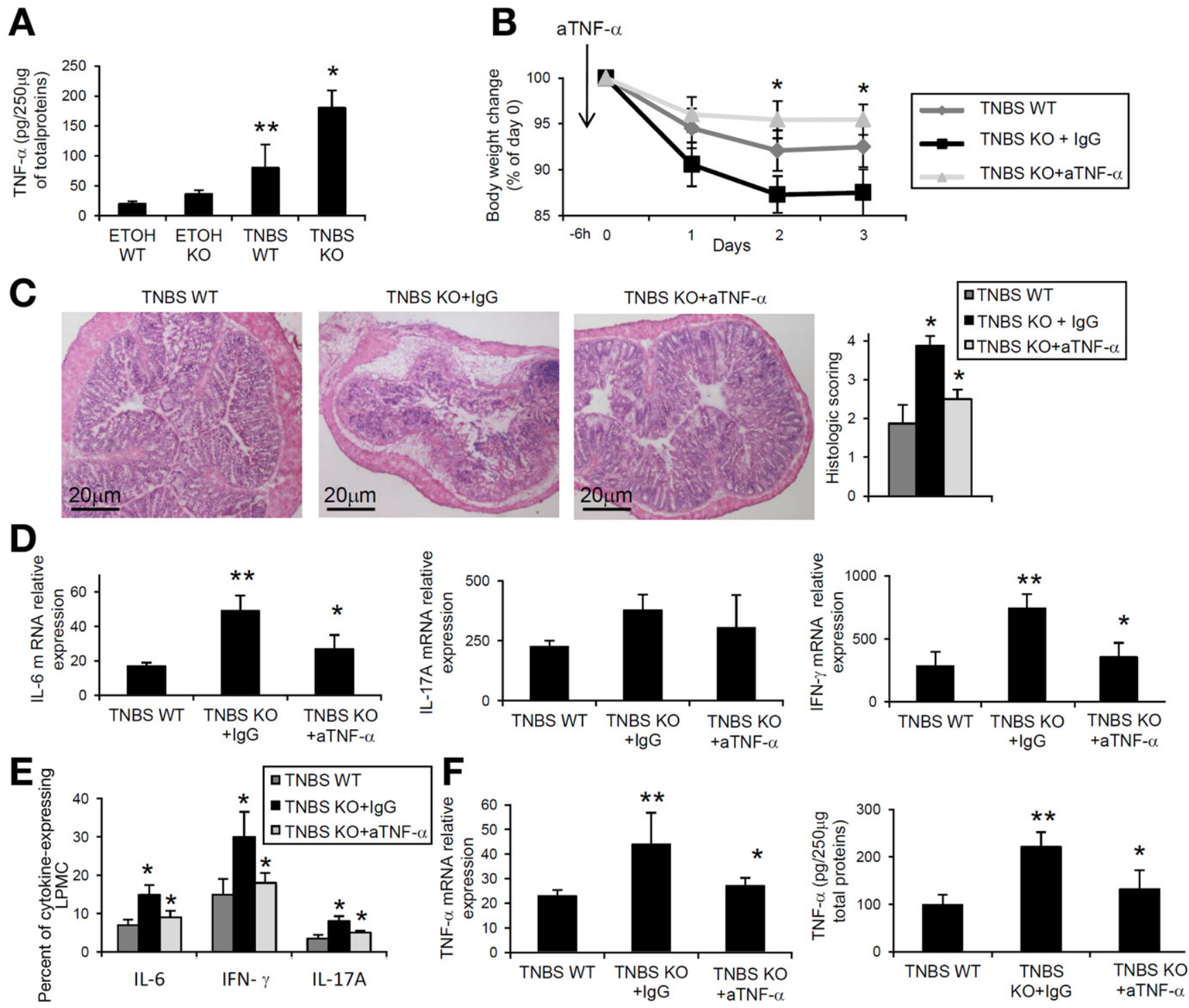

Figure 4. (A) TNF- $\alpha$ expression is enhanced in TIMP-3-KO mice with TNBS colitis. Colonic samples taken from controls (ETOH) and colitic (TNBS) WT and KO mice were analyzed for TNF- $\alpha$ by enzyme-linked immunosorbent assay. Data indicate mean \pm standard deviation of 3 separate experiments ( $\mathrm{N}=15$ mice per group): TNBS WT vs ETOH WT ( $\left.{ }^{\star *} P=.03\right)$, TNBS KO vs TNBS WT $\left({ }^{\star} P=.01\right)$. (B) Blockade of TNF- $\alpha$ ameliorates TNBS colitis in TIMP-3-KO. Anti-TNF- $\alpha$ (aTNF- $\alpha$ ) or control IgG was injected intraperitoneally to TIMP-3-KO 6 hours before the administration of TNBS (2 mg/mouse). Body weight was recorded daily. Each point on the graph indicates cumulative mean \pm standard deviation of 2 separate experiments. In each experiment at least 4 mice per group were used: IgG vs aTNF- $\alpha\left({ }^{\star} P<.03\right)$. (C) Representative H\&E-stained colonic sections and histologic score (right inset) of WT and TIMP-3-KO mice treated with aTNF- $\alpha$ or control IgG ( $\left.{ }^{\star} P=.03\right)$. (D) TIMP-3-KO mice treated with anti-TNF- $\alpha$ produce less inflammatory cytokines. Mice were treated as indicated in panel $B$ and transcripts for IL-6, IFN- $\gamma$, and IL-17A were analyzed in colonic samples by real-time polymerase chain reaction: untreated vs IgG $\left.{ }^{* \star} P=.01\right)$; anti-TNF vs $\operatorname{lgG}\left({ }^{*} P<.02\right)$. (E) LPMCs were isolated from colitic mice treated as indicated earlier and stained for IL-6, IFN- $\gamma, \mathrm{IL}-17 \mathrm{~A}$. Numbers indicate the mean value \pm standard deviation of experiments in which colonic LPMCs isolated from 6 mice for group were analyzed by fluorescence-activated cell sorter. (F) Colonic samples taken from the 3 different groups of mice treated as indicated in panel $B$ were analyzed for TNF- $\alpha$ by real-time polymerase chain reaction (right) and enzyme-linked immunosorbent assay (left): untreated vs $\lg G\left({ }^{* \star} P<.03\right)$; anti-TNF vs $\lg G\left({ }^{\star} P<.04\right)$.

enhanced TACE activity was detected in detergent extracts of cell membranes from the colonic mucosa of patients with UC but not CD. ${ }^{20}$ The reason for this discrepancy is not known but it could be related to the different methods adopted to assess the activity of ADAM regulated by TIMP-3. Our results confirm, however, studies by Cesaro et al, ${ }^{21}$ who showed that increased activity of $\alpha$-secretase in the inflamed epithelium of CD patients was associated with diminished TIMP-3 expression. Analysis of TACE expression in our samples by immunohistochemistry re- vealed no difference between IBD and controls. This finding is in line with data published by Freour et $\mathrm{al}^{30}$ showing that TACE was expressed at the same level in the intestinal epithelial compartment of IBD and normal controls. By contrast, Cesaro et $\mathrm{al}^{21}$ documented a more pronounced expression of TACE in CD as compared with normal controls. If discrepancy among these studies reflects differences in the type and severity of the mucosal inflammation and/or type of therapy used by patients remains to be ascertained. 

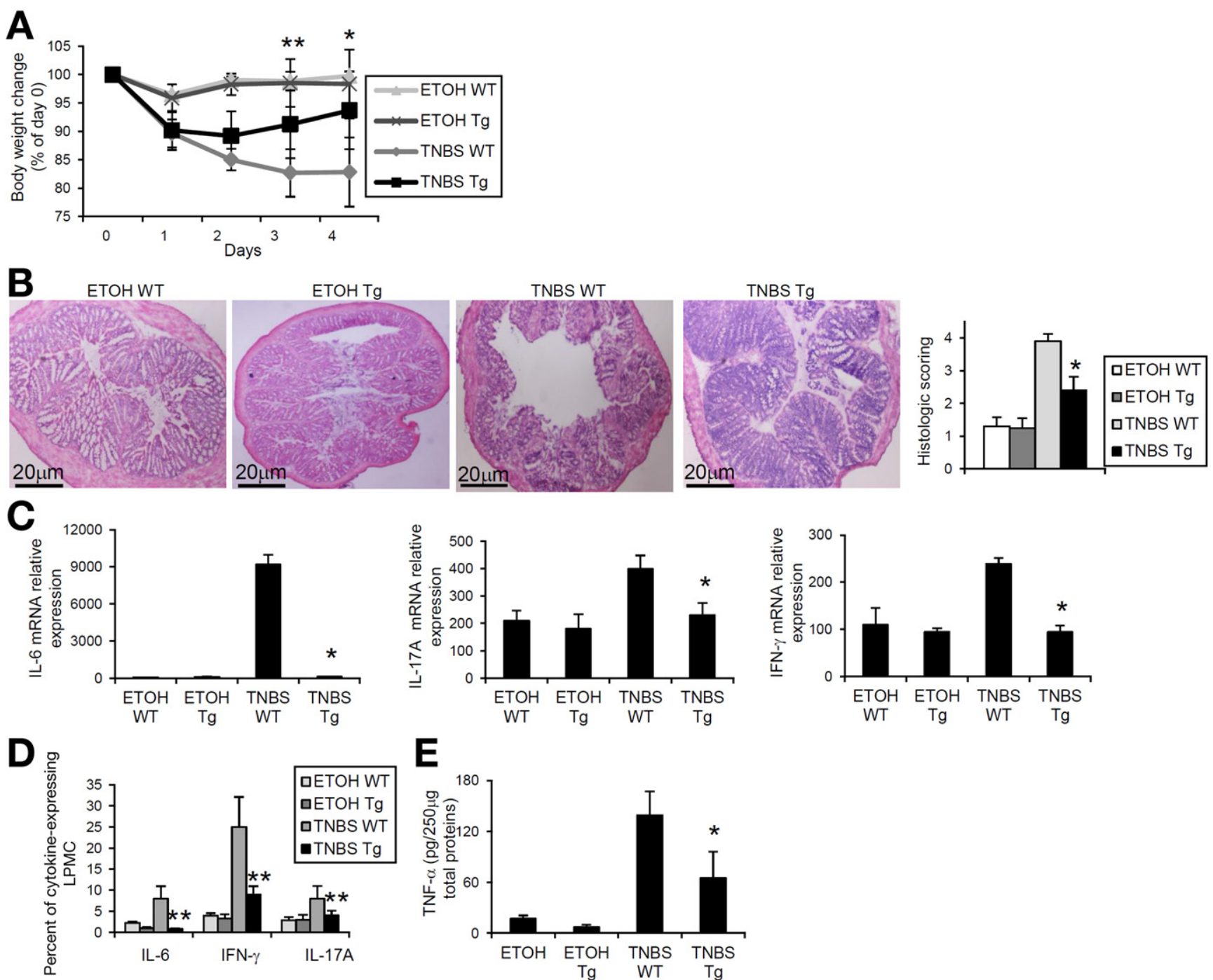

Figure 5. TIMP-3-Tg mice are resistant to TNBS colitis. (A) TNBS colitis was induced in wild-type and TIMP-3-Tg mice and body weight was recorded daily. Each point on the graph indicates cumulative mean \pm standard deviation of 2 separate experiments. In each experiment at least 5 mice per group were used. TNBS Tg vs TNBS WT $\left({ }^{\star \star} P=.03,{ }^{\star} P=.01\right)$. (B) Representative H\&E-stained colonic sections of control (ETOH-treated) and colitic (TNBS) WT and Tg mice. Right inset shows the histologic score of the colonic sections taken from the 4 groups of mice. TNBS Tg vs TNBS WT ( ${ }^{\star} P=.03$ ). (C) TIMP-3-Tg mice with TNBS colitis produce less inflammatory cytokines. Transcripts for IL-6, IFN- $\gamma$, and IL-17A in colonic samples of controls $(\mathrm{ETOH})$ and colitic WT and Tg mice as assessed by real-time polymerase chain reaction. TNBS Tg vs TNBS WT ( $\left.{ }^{*} P<.03\right)$. (D) Flow cytometry analysis of colonic LPMCs isolated from ETOH and TNBS-treated WT and Tg mice and analyzed for IL-6, IFN- $\gamma$, and IL-17A. Numbers indicate the mean value \pm standard deviation of experiments in which colonic LPMCs isolated from 6 mice for group were analyzed by fluorescenceactivated cell sorter. (E) Colonic samples taken from the 4 different groups of mice were analyzed for TNF- $\alpha$ by enzyme-linked immunosorbent assay. TNBS Tg vs TNBS WT $\left({ }^{\star} P=.03 ;{ }^{* \star} P<.04\right)$.

We have little understanding of the pathways involved in TIMP-3 regulation in the human gut, in health and disease. We show here that TGF- $\beta 1$ positively increases TIMP-3 expression in the normal gut and provides evidence suggesting that the diminished TIMP-3 expression in $\mathrm{CD}$ could be owing in part to Smad7, an inhibitor of TGF- $\beta 1$ signaling, expressed at high levels in CD mucosa. ${ }^{26}$ Indeed, knockdown of Smad7 enhanced TIMP-3 expression in both LPMC and biopsy specimens. A caveat of these studies is that analysis of TIMP-3 expression was performed in LPMCs or whole biopsy specimens and not in individual cell types. Therefore, we cannot exclude the possibility that the up-regulation of TIMP-3 seen in CD LPMCs and biopsy specimens treated with Smad7 anti- sense oligonucleotide is secondary to a decrease in inflammation mediated by endogenous TGF- $\beta 1$ inhibition. ${ }^{26,27}$ Although further studies are needed to uncouple Smad7, TGF- $\beta 1$ signaling, and TIMP- 3 in CD, our data suggest that TGF- $\beta 1$-induced TIMP-3 expression could be another pathway by which inflammation in the gut is nonspecifically dampened.

Next, we showed that rh-TIMP-3 reduced the synthesis of inflammatory cytokines but did not affect the percentage of apoptotic and regulatory $\mathrm{T}$ cells in $\mathrm{CD}$ mucosa. It thus is unlikely that the TIMP-3-mediated inhibition of inflammatory cytokines is caused by a toxic effect of the compound. Rather, this inhibitory effect could, in part, be owing to the ability of TIMP-3 to 

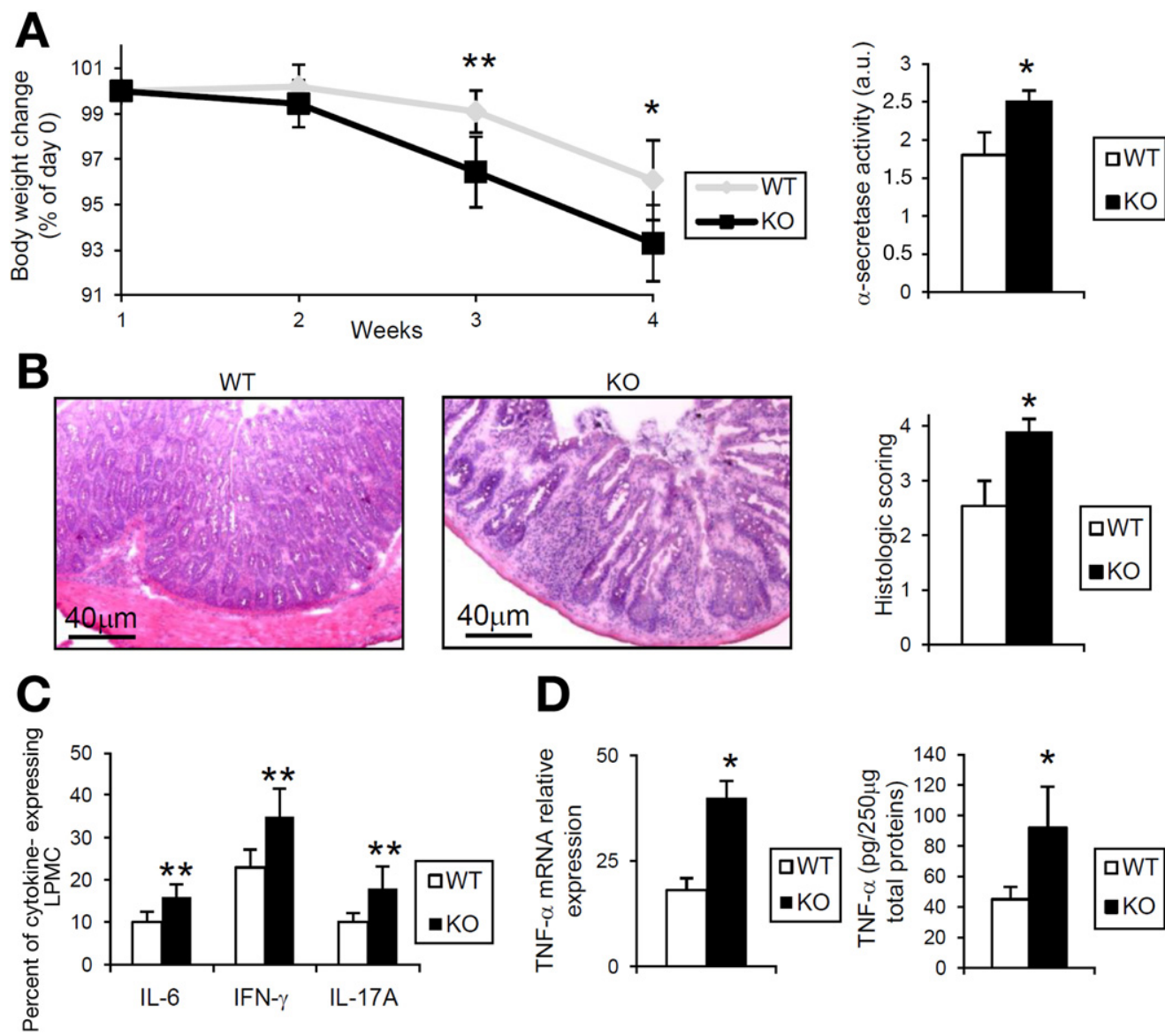

D
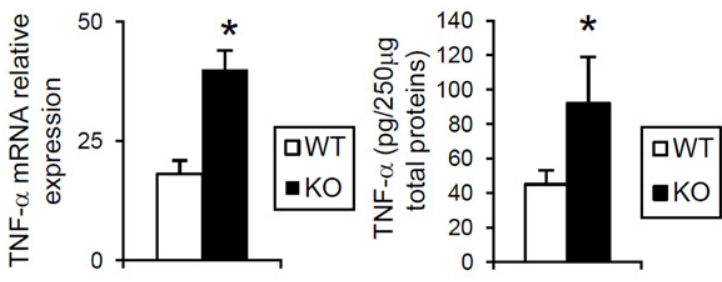

Figure 6. Transfer of TIMP-deficient naive T cells to Rag-1 KO mice causes severe colitis. Rag-1 mice were reconstituted with CD4+CD25CD62 L + cells isolated from the spleens of WT and Timp-3-KO mice and killed 4 weeks later. (A) Left: Body weight changes. Each point on the graph indicates cumulative mean \pm standard deviation of a single experiment in which 6 mice per group were considered $\left({ }^{\star \star} P=.04,{ }^{\star} P=.03\right)$. Right: $\alpha$-secretase activity in colonic tissues taken from recombinase-activating gene-1 mice reconstituted with WT or TIMP-3-KO T cells. Data indicate mean \pm standard deviation of 4 separate experiments ( $\left.{ }^{\star} P=.04\right)$. (B) Representative H\&E-stained and histologic scores (right) of the colonic sections of reconstituted mice $\left({ }^{*} P=.03\right)$. (C) Colonic samples taken from reconstituted mice were analyzed for IL-6, IFN- $\gamma$, and IL-17A by flow cytometry. Numbers indicate the mean value \pm standard deviation of experiments in which colonic LPMCs isolated from 6 mice for group were analyzed by fluorescence-activated cell sorter. (KO vs WT ${ }^{*} \mathrm{P}<$.04). (D) Colonic samples taken from the 2 different groups were analyzed for TNF- $\alpha$ by real-time polymerase chain reaction (left) and enzyme-linked immunosorbent assay (right) $\left.{ }^{*} P<.03\right)$.

cleave LAG3 from activated T cells and suppress T-cell activation. ${ }^{10}$ The effect of exogenous TIMP-3 in reducing cytokines other than TNF- $\alpha$ also may be explained by the fact that there is convincing evidence that TNF- $\alpha$ is a master cytokine, feeding back to macrophages to maintain production of IL-6. ${ }^{31}$ Indeed, this was much of the rationale for the use of anti-TNF- $\alpha$ antibodies in rheumatoid arthritis and CD. ${ }^{32}$

In a final set of experiments, we determined if loss of TIMP-3 could alter experimental colitis in mice. Wild-type mice with TNBS colitis showed much reduced TIMP-3 and high $\alpha$-secretase activity. Interestingly, TIMP-3-deficient mice developed a very severe TNBS colitis, associated with increased expression of inflammatory cytokines. In contrast, TIMP-3-Tg mice expressed less inflammatory cytokines and were largely resistant against TNBS colitis, and transfer of TIMP-3-deficient $\mathrm{T}$ cells into immunodeficient recipients produced severe colitis with high Th1and Th17-related cytokines, IL-6, and TNF- $\alpha$. Altogether these results indicate that TIMP- 3 is a negative regulator of intestinal inflammation. TNF- $\alpha$ seems to be central in the TIMP-3-mediated negative control of gut inflammation because blockade of TNF- $\alpha$ with a neutralizing antibody in TIMP-3-KO mice attenuated TNBS colitis.

TIMP-3 negatively regulates not only TACE but also the functional activity of MMPs, which are increased in IBD. There is some evidence that MMP-9 derived from the epithelium is crucial in the induction of intestinal damage, ${ }^{33}$ thus one could speculate that the more severe phenotype seen in TIMP-3-KO mice after TNBS administration also may be owing to the lack of inhibitory effect of TIMP-3 on MMP-9 activity. Unfortunately, there are no commercial compounds that selectively inhibit MMP-9 and ADAMs to assess the exact contribution of different proteases in the colitis occurring in TIMP-3-KO mice.

Mice engineered to have barely detectable levels of TACE in all tissues show enhanced susceptibility to develop colitis after oral administration of dextran sulfate sodium. ${ }^{34}$ This would seem to be the consequence of impaired epidermal growth factor receptor (EGFR)-de-

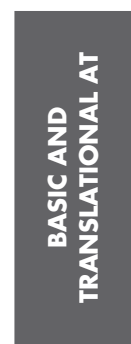


pendent regeneration of the epithelium caused by failure of shedding of EGFR ligands, and is consistent with the similar abnormality seen in mice with global deletion of TACE who are embryonic and neonatal lethal. ${ }^{7}$ Analysis of inflammatory cytokines in colon organ cultures from dextran sulfate sodium-treated animals showed, however, that TACE deficiency is associated with high IL-11, a cytokine thought to be cytoprotective in the gut, but no significant change in the production of TNF- $\alpha$, Th17related cytokines, and IL-12, the major inducer of IFN- $\gamma .{ }^{34}$ Therefore, it is conceivable that the decreased expression of TIMP-3 in the epithelial compartment either can contribute to amplify the ongoing mucosal inflammation through a TACE-driven TNF- $\alpha$-dependent mechanism or exert a regulatory effect on the epithelial barrier by modulating TACE-dependent shedding of EGFR ligands.

TACE has been considered to be a drug target for chronic inflammatory diseases and a number of compounds have been developed with some selectivity. ${ }^{35}$ The relative contribution of membrane-bound TNF- $\alpha$ compared with soluble TNF- $\alpha$ to chronic inflammation is still not understood. As mentioned earlier, the critical role of TACE in epithelial renewal at mucosal sites also detracts from its clinical use. A TACE-deficient child recently was identified who after initial gut problems survived into late adolescence, although he has skin pathology and infections. ${ }^{36}$ The child still produces some TNF- $\alpha$ when his monocytes are activated with lipopolysaccharide, perhaps owing to the TNF- $\alpha$ convertase activity of other ADAMs. Taken together with the results presented here, there may be a rationale for the clinical use of TIMP-3 in inflammatory diseases.

In conclusion, our findings show that TIMP-3 delivers anti-inflammatory signals in the gut and delineate a novel mechanism by which production of inflammatory cytokines and pathology can be inhibited during inflammatory disorders of the intestine.

\section{Supplementary Material}

Note: To access the supplementary material accompanying this article, visit the online version of Gastroenterology at www.gastrojournal.org, and at http:// dx.doi.org/10.1053/j.gastro.

\section{References}

1. Kaser A, Zeissig S, Blumberg RS. Inflammatory bowel disease. Annu Rev Immunol 2010;28:573-621.

2. von Lampe B, Barthel B, Coupland SE, et al. Differential expression of matrix metalloproteinases and their tissue inhibitors in colon mucosa of patients with inflammatory bowel disease. Gut 2000;47:63-73.

3. Heuschkel RB, MacDonald TT, Monteleone G, et al. Imbalance of stromelysin-1 and TIMP-1 in the mucosal lesions of children with inflammatory bowel disease. Gut 2000;47:57-62.

4. Monteleone G, Caruso R, Fina D, et al. Control of matrix metalloproteinase production in human intestinal fibroblasts by interleukin 21. Gut 2006;55:1774-1780.

5. Pender SL, Li CK, Di Sabatino A, et al. Role of macrophage metalloelastase in gut inflammation. Ann N Y Acad Sci 2006; 1072:386-388.
6. Makitalo L, Kolho KL, Karikoski R, et al. Expression profiles of matrix metalloproteinases and their inhibitors in colonic inflammation related to pediatric inflammatory bowel disease. Scand J Gastroenterol 2010;45:862-871.

7. Black RA, Rauch CT, Kozlosky CJ, et al. A metalloproteinase disintegrin that releases tumour-necrosis factor-alpha from cells. Nature 1997;385:729-733.

8. Reddy P, Slack JL, Davis R, et al. Functional analysis of the domain structure of tumor necrosis factor-alpha converting enzyme. J Biol Chem 2000;275:14608-14614.

9. Murphy G, Murthy A, Khokha R. Clipping, shedding and RIPping keep immunity on cue. Trends Immunol 2008;29:75-82.

10. Li N, Wang $\mathrm{Y}$, Forbes $\mathrm{K}$, et al. Metalloproteases regulate T-cell proliferation and effector function via LAG-3. EMBO J 2007;26: 494-504.

11. Weskamp G, Ford JW, Sturgill J, et al. ADAM10 is a principal 'sheddase' of the low-affinity immunoglobulin E receptor CD23. Nat Immunol 2006;7:1293-1298.

12. Melenhorst WB, van den Heuvel MC, Stegeman CA, et al. Upregulation of ADAM19 in chronic allograft nephropathy. Am J Transplant 2006;6:1673-1681.

13. Holloway JW, Laxton RC, Rose-Zerilli MJ, et al. ADAM33 expression in atherosclerotic lesions and relationship of ADAM33 gene variation with atherosclerosis. Atherosclerosis 2010; 211:224-230.

14. Tarlton JF, Whiting CV, Tunmore D, et al. The role of up-regulated serine proteases and matrix metalloproteinases in the pathogenesis of a murine model of colitis. Am J Pathol 2000;157:19271935.

15. Itoh T, Matsuda H, Tanioka M, et al. The role of matrix metalloproteinase- 2 and matrix metalloproteinase- 9 in antibody-induced arthritis. J Immunol 2002;169:2643-2647.

16. Menghini R, Menini S, Amoruso R, et al. Tissue inhibitor of metalloproteinase 3 deficiency causes hepatic steatosis and adipose tissue inflammation in mice. Gastroenterology 2009;136:663672 e4.

17. Fiorentino L, Vivanti A, Cavalera M, et al. Increased tumor necrosis factor alpha-converting enzyme activity induces insulin resistance and hepatosteatosis in mice. Hepatology 2010;51:103-110.

18. Gill SE, Huizar I, Bench EM, et al. Tissue inhibitor of metalloproteinases 3 regulates resolution of inflammation following acute lung injury. Am J Pathol 2010;176:64-73.

19. Mahmoodi M, Sahebjam S, Smookler D, et al. Lack of tissue inhibitor of metalloproteinases-3 results in an enhanced inflammatory response in antigen-induced arthritis. Am J Pathol 2005; 166:1733-1740.

20. Brynskov J, Foegh P, Pedersen G, et al. Tumour necrosis factor alpha converting enzyme (TACE) activity in the colonic mucosa of patients with inflammatory bowel disease. Gut 2002;51:37-43.

21. Cesaro A, Abakar-Mahamat A, Brest $P$, et al. Differential expression and regulation of ADAM17 and TIMP3 in acute inflamed intestinal epithelia. Am J Physiol Gastrointest Liver Physiol 2009; 296:G1332-G1343.

22. Colon AL, Menchen LA, Hurtado O, et al. Implication of TNF-alpha convertase (TACE/ADAM17) in inducible nitric oxide synthase expression and inflammation in an experimental model of colitis. Cytokine 2001;16:220-226.

23. Geboes K, Riddell R, Ost A, et al. A reproducible grading scale for histological assessment of inflammation in ulcerative colitis. Gut 2000;47:404-409.

24. D'Haens GR, Geboes K, Peeters M, et al. Early lesions of recurrent Crohn's disease caused by infusion of intestinal contents in excluded ileum. Gastroenterology 1998;114:262-267.

25. Monteleone G, Biancone L, Marasco R, et al. Interleukin 12 is expressed and actively released by Crohn's disease intestinal lamina propria mononuclear cells. Gastroenterology 1997;112: 1169-1178. 
26. Monteleone G, Kumberova A, Croft NM, et al. Blocking Smad7 restores TGF-beta1 signaling in chronic inflammatory bowel disease. J Clin Invest 2001;108:601-609.

27. Boirivant M, Pallone F, Di Giacinto C, et al. Inhibition of Smad7 with a specific antisense oligonucleotide facilitates TGF-beta1mediated suppression of colitis. Gastroenterology 2006;131: 1786-1798.

28. Asseman C, Read S, Powrie F. Colitogenic Th1 cells are present in the antigen-experienced T cell pool in normal mice: control by CD4+ regulatory T cells and IL-10. J Immunol 2003;171:971-978.

29. Garcia-Alvarez J, Ramirez R, Checa M, et al. Tissue inhibitor of metalloproteinase-3 is up-regulated by transforming growth factorbeta1 in vitro and expressed in fibroblastic foci in vivo in idiopathic pulmonary fibrosis. Exp Lung Res 2006;32:201-214.

30. Freour T, Jarry A, Bach-Ngohou K, et al. TACE inhibition amplifies TNF-alpha-mediated colonic epithelial barrier disruption. Int J Mol Med 2009;23:41-48.

31. Tracey KJ, Cerami A. Tumor necrosis factor: a pleiotropic cytokine and therapeutic target. Annu Rev Med 1994;45:491-503.

32. Brennan FM, Feldmann M. Cytokines in autoimmunity. Curr Opin Immunol 1996;8:872-877.

33. Garg P, Vijay-Kumar M, Wang L, et al. Matrix metalloproteinase-9mediated tissue injury overrides the protective effect of matrix metalloproteinase-2 during colitis. Am J Physiol Gastrointest Liver Physiol 2009;296:G175-G184.

34. Chalaris A, Adam N, Sina C, et al. Critical role of the disintegrin metalloprotease ADAM17 for intestinal inflammation and regeneration in mice. J Exp Med 2010;207:1617-1624.

35. DasGupta S, Murumkar PR, Giridhar R, et al. Current perspective of TACE inhibitors: a review. Bioorg Med Chem 2009;17:444459.
36. Blaydon DC, Biancheri P, Di WL, et al. Inflammatory skin and bowel disease linked to ADAM17 deletion. N Engl J Med 2011;365: 1502-1508.

Received October 25, 2011. Accepted July 10, 2012.

\section{Reprint requests}

Address requests for reprints to: Giovanni Monteleone, MD, Dipartimento di Medicina Interna, Università Tor Vergata, Via Montpellier, 1, 00133 Rome, Italy. e-mail: Gi.Monteleone@ Med.uniroma2.it; fax: (39) 06-72596391.

\section{Acknowledgments}

The authors thank Rama Khokha for kindly providing the tissue inhibitor of metalloproteinases-3- deficient mice.

GM and TTM are both co-senior authors of the study.

\section{Conflicts of interest}

The authors disclose no conflicts.

\section{Funding}

This work was supported by Fondazione Umberto Di Mario Onlus (Rome, Italy), Giuliani Spa (Milan, Italy), funding for the Opportunity for Drug Discovery consortium under Grant Agreement 202020 of the Seventh Research Framework Programme of the European Union; and by Telethon GGP08065, Fondazione Roma 2008, Juvenile Diabetes Research Foundation RRG 1-2007-665, FP7-Health241913, The role of intestinal microflora in non-alcoholic fatty liver disease, and the Ministry of Health RF 2007. 


\section{Supplementary Materials and Methods}

\section{RNA Extraction, Complementary DNA \\ Preparation, and Real-Time Polymerase Chain Reaction}

RNA was extracted using TRIzol reagent according to the manufacturer's instructions (Invitrogen). Polymerase chain reaction was performed using a SYBR green-based polymerase chain reaction (Bio-Rad, Hercules, CA). A constant amount of RNA (1 $\mu$ g per sample) was reverse-transcribed into complementary DNA, and amplified using the following conditions: denaturation for 1 minute at $95^{\circ} \mathrm{C}$, annealing for 30 seconds at $62^{\circ} \mathrm{C}$ for human TNF- $\alpha, 61^{\circ} \mathrm{C}$ for human IL-17A, $58^{\circ} \mathrm{C}$ for human IFN- $\gamma$, mouse TNF- $\alpha$, mouse IFN- $\gamma$, mouse IL-17A, and $60^{\circ} \mathrm{C}$ for human and mouse IL- 6 and $\beta$-actin followed by a 30 -second extension at $72^{\circ} \mathrm{C}$. Primer sequences were as follows: human TNF- $\alpha$ forward, 5'-ACTACA ACCGATCCACCTCAC-3', reverse, 5' -GGCTACAGGCTTGTCACTCG-3'; human IL-6 forward, 5'-CCACTCACСТCTTCAGAACG-3', reverse, 5'-GCCTCTTTGCTGCTTTCACAC-3'; human IL-17A, forward, 5'-ACTACAACCGATCCACCTCAC-3', reverse, 59-ACTTTGCCTCCCAGATCACAG-39; human IFN- $\gamma$, forward, 5' -TGGAGACCATCAAGGAAGAC-3', reverse 5'-GCGTTGGACATTCAAGTCAG-3'.

Mouse IL-17A, forward, 5'-TCAGACTACCTCAACCGTTC3', reverse, 5'-TTCAGGACCAGGATCTCTTG-3'; mouse IFN- $\gamma$, forward, $5^{\prime}$-CAATGAACGCTACACACTGC-3', reverse, $3^{\prime}$-GAGTTCACCGTATCTACACC-5'; mouse TNF- $\alpha$, forward, 5'-ACCCTCACACTCAGATCATC-3', reverse, 5'-GAGTAGACAAGGTACAACCC-3'; mouse IL-6, forward, 5'-AGCCAGAGTCCTTCAGAGAG-3', reverse, 5' - GATGGTCTTGGTCCTTAGCC-3'. Human and mouse Timp-3 and human TACE and ADAM-15 were evaluated using commercially available TaqMan probes (Applied Biosystems, Foster City, CA). $\beta$-actin (forward: $5^{\prime}$-AAGATGACCCAGATCATGTTTGAGACC$3^{\prime}$, and reverse: 5'-AGCCAGTCCAGACGCAGGAT-3') was used as a housekeeping gene. Gene expression was calculated using the $\Delta \Delta$ cycle threshold (CT) algorithm.

\section{Immunobistochemistry}

Frozen sections taken from 6 patients with CD, 6 patients with UC, and 6 normal controls were incubated with a mouse anti-human TIMP-3 antibody (Merck Millipore, Billerica, MA), or mouse anti-human TACE antibody (Merck Millipore) for 1 hour at room temperature. Immunoreactive cells were visualized using MACH4 Universal horseradish peroxidase Polymer kit with 3,3'-diaminobenzidine (Biocare Medical, Concord CA), according to the manufacturer's instructions, and lightly counterstained with hematoxylin. Isotype control sections were prepared under identical immunohistochemical conditions, replacing the primary antibody with a purified, normal mouse IgG control antibody (Dako Italia, Milan, Italy).

\section{TIMP-3 Knockout and Transgenic Mice}

The TIMP-3 null mice (KO) have been described previously. ${ }^{1}$ Generation of MacT3 $\mathrm{Tg}$ mice has been described previously. ${ }^{2,3}$ Briefly, 3 transgenic lines (Tg1, Tg3, and $\operatorname{Tg} 5$ ) were produced and 2 different transgenic lines were characterized in the original studies with comparable levels of expression of TIMP-3 (Tg3 and Tg5). In these lines, TIMP-3 overexpression was 2 -fold compared with controls in lipopolysaccharide-stimulated cells in vitro and in inflamed tissues in vivo. In this study we used the transgenic line Tg3. In our previous study we performed a cell-specific assay showing that TIMP-3 was overexpressed in monocytes and to a minor extent granulocytes (all CD68+), but not in parenchymal cells (such as adipocytes and hepatocytes). The CD68 genomic fragment has been described and used for the generation of different transgenic lines. ${ }^{4}$ Mouse TIMP-3 gene was amplified by polymerase chain reaction using complementary DNA obtained from mouse muscle as a template, cloned in a vector containing CD68 promoter/enhancer, and amplified in Escherichia coli strain DH5 $\alpha$. For Tg mice generation, the construct was linearized with endonuclease enzymes (EcoRV/StuI) and microinjected into mouse pronuclei by standard methods. Offspring derived from the injections was genotyped by polymerase chain reaction amplifying a 300-bp fragment of CD68 promoter and the murine TIMP-3 gene on DNA isolated from tail biopsy. Southern blotting of EcoRV digested DNA, followed by probing the membrane with the CD68-TIMP-3 fragment labeled with $[\alpha-32 \mathrm{P}]$-deoxycytidine triphosphate, confirmed the polymerase chain reaction results. For hematopoietic cell lineage distribution, peripheral blood was collected from the tail vein and analyzed on a blood cell analyzer (Simply Cell; BPC BioSed, Rome, Italy) to determine cell counts.

\section{Flow Cytometry}

Human LPMCs were stained with the following antibodies: anti-CD3-PerCP (1:50, final dilution; BD Biosciences, San Jose, CA), anti-TIMP-3-Pe (1:50, final dilution; BD Biosciences), anti-Ly-6G-fluorescein isothiocyanate (1:50, final dilution; BD Biosciences), and anti-CD19-fluorescein isothiocyanate (1:50, final dilution; BD Biosciences). To assess the expression of $\mathrm{mTNF}-\alpha$, cells were incubated with infliximab $(1 \mu \mathrm{g} / \mathrm{mL})$ followed by anti-human IgG1-fluorescein isothiocyanate (BD Biosciences) used as a secondary antibody. To assess the intracellular expression of CD68, Smad7, or FoxP-3, cells were fixed with $1 \%$ formaldehyde for 20 minutes and permeabilized with $5 \%$ of saponin in $1 \%$ bovine serum albumin fluorescence-activated cell sorter buffer and stained with anti-CD68-APC (1:50 final dilution; BD Biosciences), anti-Smad7 (1:50 final dilution; BD Biosciences), followed by anti-mouse-IgG1-fluorescein isothiocyanate (BD Biosciences) or anti-FoxP-3-PE (1:50, final dilution; eBioscience, San Diego, CA). To assess the per- 
centage of Annexin-V/propidium iodide-positive cells, LPMCs were resuspended in $50 \mu \mathrm{L}$ binding buffer solution $(10 \mathrm{mmol} / \mathrm{L}$ HEPES/NaOH, pH 7.4, $140 \mathrm{mmol} / \mathrm{L}$ $\mathrm{NaCl}, 2.5 \mathrm{mmol} / \mathrm{L} \mathrm{CaCl}{ }_{2}$ ) containing $1 \mu \mathrm{L}$ fluorescein isothiocyanate-conjugated $\mathrm{AV}$ (BD Biosciences) and 1 $\mu \mathrm{g} / \mathrm{mL}$ propidium iodide (BD Biosciences).

Murine LPMCs were resuspended in complete medium, seeded in 96-well U-bottom culture dishes, and stimulated with phorbol-12-myristate-13-acetate (10 $\mathrm{ng} / \mathrm{mL})$, ionomycin $(1 \mu \mathrm{g} / \mathrm{mL})$, and brefeldin A (10 $\mu \mathrm{g} / \mathrm{mL}$; eBioscience). After 5 hours, cells were stained intracellularly with the following antibody: anti-IFN$\gamma$-PE (1:50, final dilution; BD Biosciences), anti-IL17A-allophycocyanin (1:50, final dilution; eBioscience), and anti-IL-6-fluorescein isothiocyanate (1:50, final dilution; eBioscience). Appropriate isotypematched controls from BD Biosciences were included in all experiments. Cells were analyzed using a FACSCalibur cytometer and Cell-QuestPro software (BD Bioscience).

\section{Enzyme-Linked Immunosorbent Assay for TNF- $\alpha$}

Total proteins were extracted from colons of mice as previously described and analyzed for the content of TNF- $\alpha$ using a sensitive enzyme-linked immunosorbent assay kit according to the manufacturer's protocol (R\&D Systems).

\section{References}

1. Leco KJ, Waterhouse $\mathrm{P}$, Sanchez $\mathrm{OH}$, et al. Spontaneous air space enlargement in the lungs of mice lacking tissue inhibitor of metalloproteinases-3 (TIMP-3). J Clin Invest 2001;108:817-829.

2. Casagrande V, Menghini R, Menini S, et al. Overexpression of tissue inhibitor of metalloproteinase 3 in macrophages reduces atherosclerosis in low-density lipoprotein receptor knockout mice. Arterioscler Thromb Vasc Biol 2012;32:74-81.

3. Menghini R, Casagrande V, Menini S, et al. TIMP3 overexpression in macrophages protects from insulin resistance, adipose inflammation, and nonalcoholic fatty liver disease in mice. Diabetes 2012;61:454462.

4. Lang R, Rutschman RL, Greaves DR, et al. Autocrine deactivation of macrophages in transgenic mice constitutively overexpressing IL-10 under control of the human CD68 promoter. J Immunol 2002;168:3402-3411. 

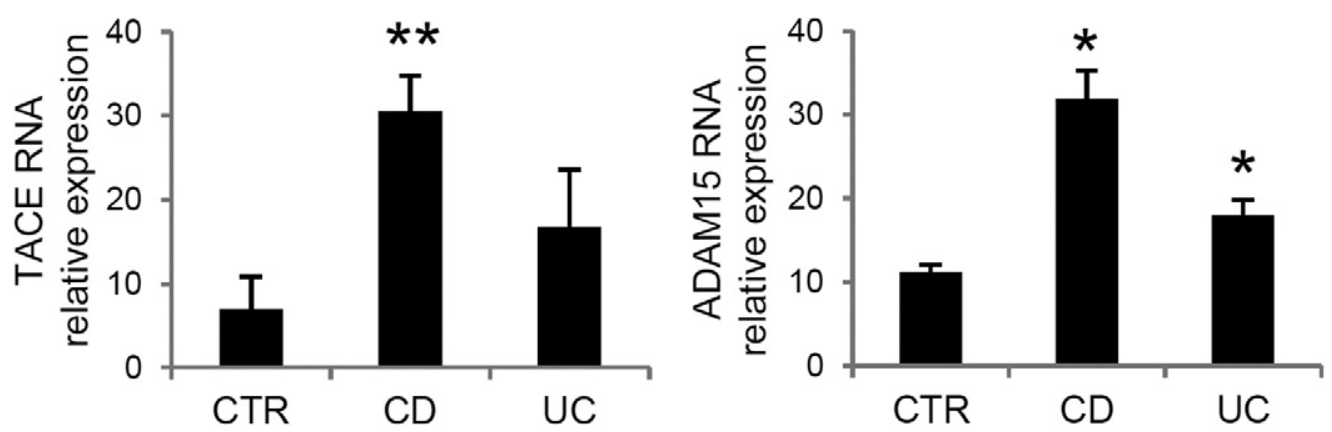

Supplementary Figure 1. RNA expression for TACE (right) and ADAM-15 (left) were evaluated in biopsy specimens taken from 12 normal controls (CTR), 12 patients with $C D(C D)$, and 10 patients with $U C(\mathrm{UC})$ by real-time polymerase chain reaction and normalized to $\beta$-actin. CD vs CTR (** $P=$ $.02), \mathrm{CD}$ vs UC ( $\left.{ }^{\star} P=.03\right), \mathrm{CD}$ vs $\mathrm{CTR}\left({ }^{\star} P=.02\right)$, and UC vs CTR ( $\left.{ }^{\star} P=.04\right)$.

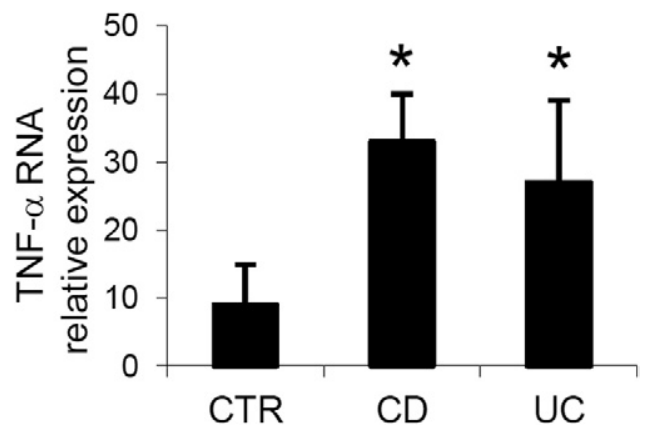

Supplementary Figure 2. TNF- $\alpha$ RNA expression is increased in CD and UC mucosa. Transcripts for TNF- $\alpha$ were evaluated in biopsy specimens taken from 12 normal controls (CTR), 12 patients with CD (CD), and 12 patients with UC (UC) by real-time polymerase chain reaction and normalized to $\beta$-actin. Data indicate mean \pm standard deviation of all experiments. CD or UC vs CTR $\left({ }^{\star} P<.02\right)$.
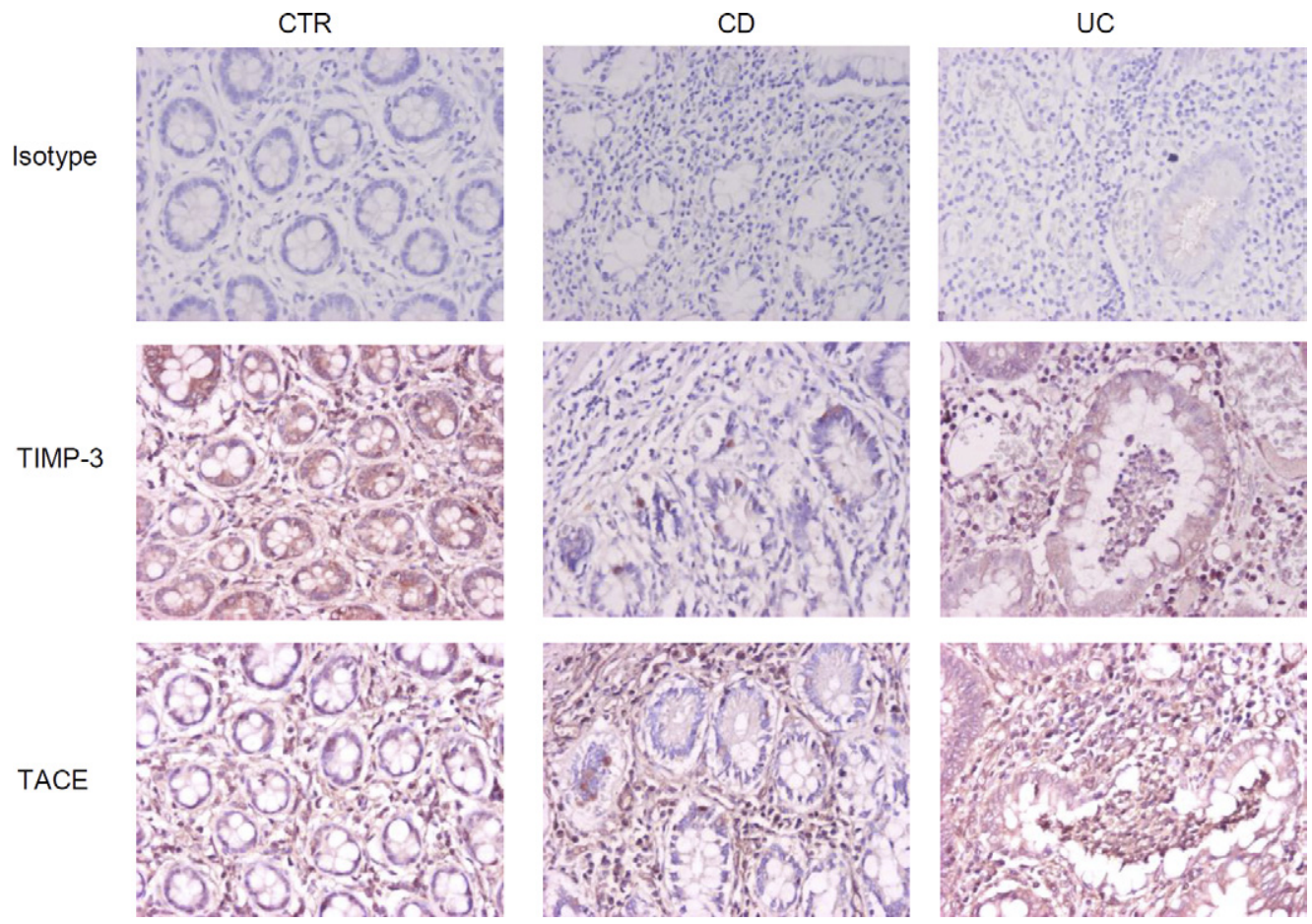

Supplementary Figure 3. TIMP-3 and TACE immunostaining in intestinal specimens from 1 normal control (CTR), 1 patient with CD, and 1 patient with UC. The figure is representative of 3 separate experiments in which sections of 6 normal controls, 6 patients with CD, and 6 patients with UC were analyzed. Isotype control staining is indicated. 
A

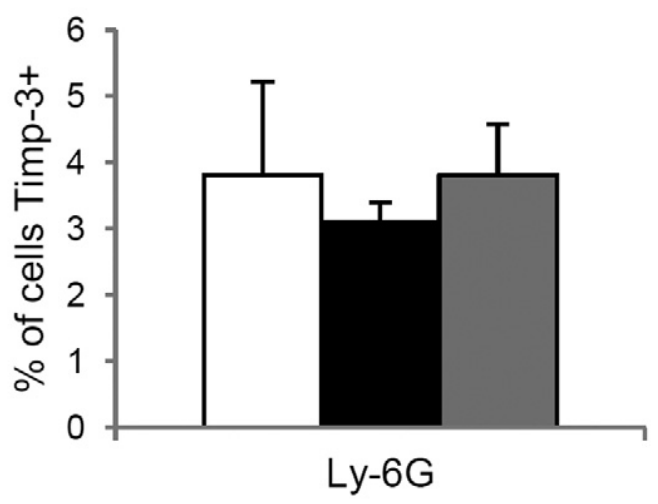

$B$

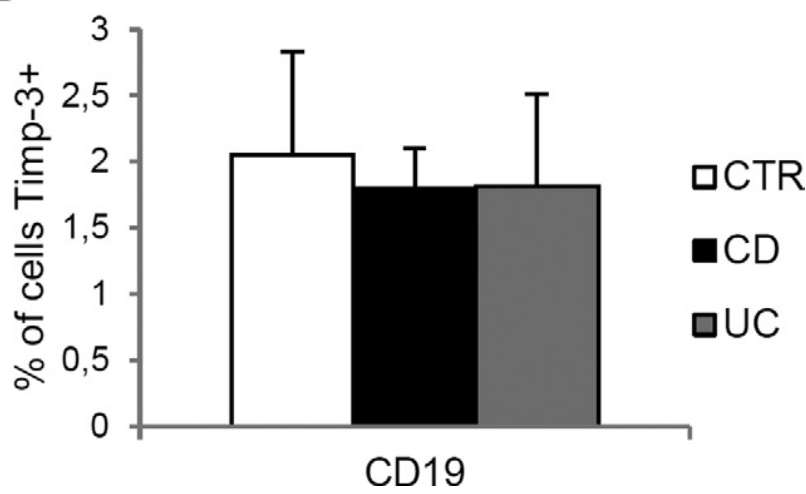

Supplementary Figure 4. Flow cytometry analysis of TIMP-3 in Ly$6 \mathrm{G}+\mathrm{CD} 68$ - and CD19+ colonic cells isolated from 4 normal controls (CTR), 4 CD patients, and 4 UC patients. Data indicate mean \pm standard deviation of all experiments.
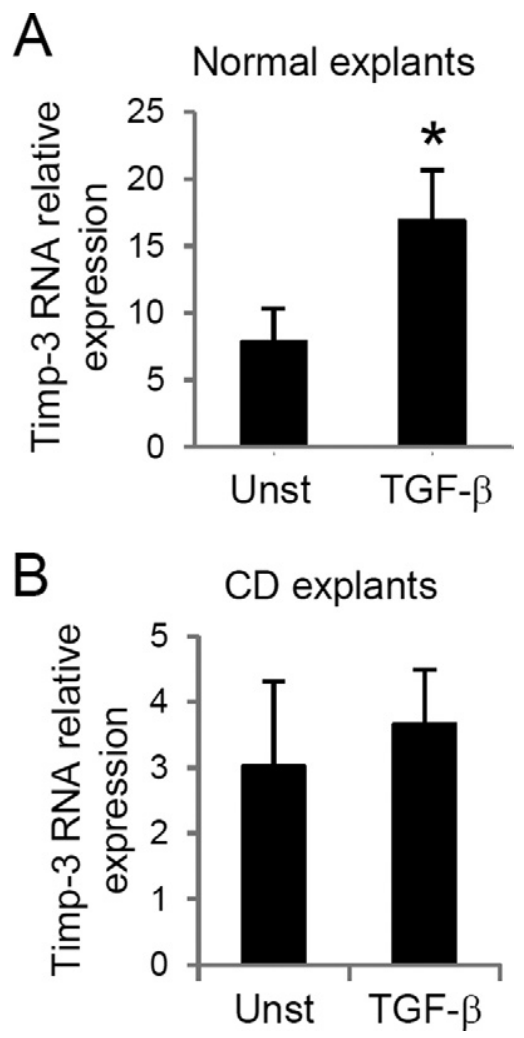

Supplementary Figure 5. TGF- $\beta 1$-enhanced TIMP-3 in normal gut. Colonic mucosal samples taken from $(B) 4$ normal controls and $(C) 2 \mathrm{CD}$ patients were incubated with TGF- $\beta 1$ for 24 hours and then examined for TIMP-3 by real-time polymerase chain reaction. Data indicate mean \pm standard deviation of all experiments $\left({ }^{\star} P=.03\right)$.

A

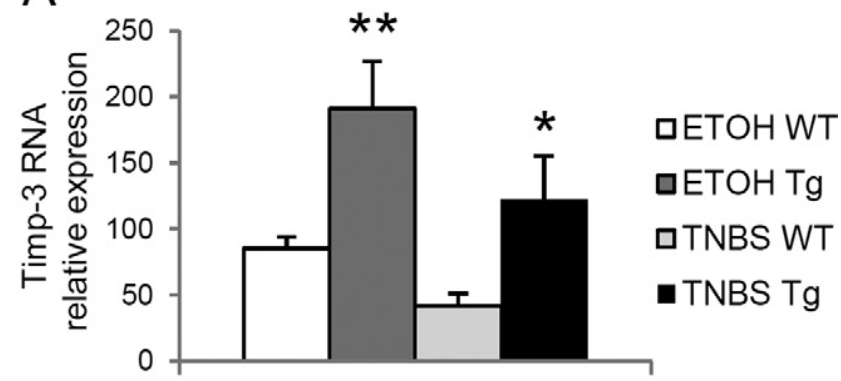

B

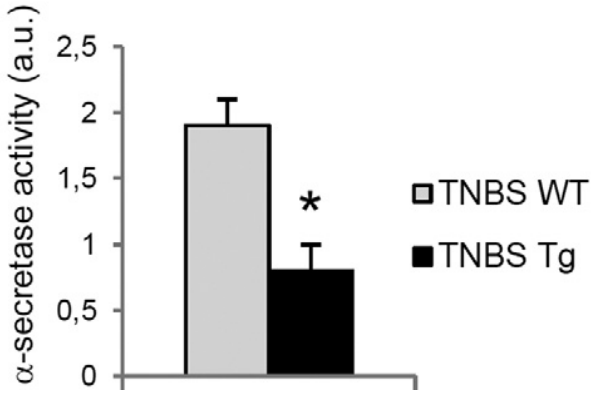

Supplementary Figure 6. (A) TIMP-3 RNA expression in colon tissues taken from control (ETOH) and colitic (TNBS) WT and Tg mice. $\mathrm{ETOH}$ WT vs ETOH Tg $\left({ }^{\star *} P=.01\right)$, TNBS Tg vs TNBS WT $\left({ }^{*} P=.03\right)$, and ETOH Tg vs TNBS Tg $(P=.04)$. (B) $\alpha$-secretase activity in WT and TIMP-3-Tg mice with TNBS colitis. Data were normalized to the activity of TACE in ETOH-treated mice $\left({ }^{\star} P=.03\right)$. 